\title{
Evaluation of Bone Mineral Density among type 2 Diabetes Mellitus Patients in Zagazig University Hospitals \\ Abdelmonem Fathy Zeid ${ }^{1}$, Amira Shoukry Ahmed ${ }^{1}$, Mina Talaat Shohdy*1, Mostafa Mohamed Hamdy Asssy ${ }^{2}$ \\ ${ }^{1}$ Internal Medicine Department, ${ }^{2}$ Radiology Department, Faculty of Medicine, Zagazig University *Corresponding Author: Mina Talaat Shohdy, Phone No.: (+2) 01210329498, E-mail: minatalaatmed@gmil.com
}

\begin{abstract}
Background: Diabetes is one of the biggest health problems worldwide where the disease affects almost all organ systems. The relationship between type 2 diabetes mellitus (T2DM) and bone mineral density (BMD) has been controversial. Some show increased, decreased and others show no change in BMD among type 2 diabetics.

Objective: The aim of the study was to assess the effect of T2DM on BMD among diabetic patients in Zagazig University Hospitals. Also, evaluation of the effect of other factors like menopause, age and gender that may interfere with DM on BMD.

Materials and methods: A case control study that was conducted on 90 individuals. Their ages ranged between 40 and 70 years and consisted of 60 diabetic and 30 nondiabetic subjects. BMD was measured using DEXA scan and the data were compared among age-matched subjects of both groups.

Results: BMD was significantly decreased among diabetic patients matched to those who are non-diabetics. Also, the incidence of osteopenia and osteoporosis was higher among diabetic patients. On further analysis of date the highest percent of abnormal BMD (osteopenia and osteoporosis) was among diabetic postmenopausal female cases. Conclusion: Type 2 DM negatively affect the bone strength through affection of BMD. Hence, all type 2 diabetics should be evaluated for the risk of osteoporosis and should be offered appropriate preventive measures.
\end{abstract}

Key words: Bone Mineral Density, Osteoporosis, DEXA scan, Type 2 diabetes, Menopause

\section{INTRODUCTION}

Diabetes has evolved as one of the biggest health problems worldwide and the disease affects almost all organ systems. Diabetes mellitus is a metabolic disorder resulting from a defect in insulin secretion, insulin action, or both. Osteoporosis is a silent disease with a harmful impact on bone health. Endocrine and metabolic alterations in diabetes mellitus can trigger disorders of calcium homeostasis, skeletal metabolism and bone mass. Most studies indicate that type $1 \mathrm{DM}$ is associated with decreased bone mineral density (BMD) (1) and more than $50 \%$ of them are osteoporotic what is called diabetic osteoporosis ${ }^{(2)}$, but with type 2 DM the situation is different, some authors report increased, some report decreased and some others report no change in BMD ${ }^{(3)}$. Early identification of reduction in bone mass in a diabetic patient may be helpful in preventing the bone loss and future fracture risk. BMD has been identified as a key determinant of future fracture risks ${ }^{(4)}$.

Diabetic osteopathy may need attention as one of the common disease complications. Recently, osteoporosis is the most significant metabolic bone disease in patients with diabetes mellitus ${ }^{(5)}$. Even diabetic patients who have higher BMD, are also at increased risk of fracture due to higher risk of falling related to diabetic complications as retinopathy and vasculpathy and not to diabetes itself. Diabetes could influence bone through several mechanisms, some of which may have positive, others have negative effect on bone density. Higher levels of advanced glycation end-products (AGEs) in collagen fibers of diabetic patient interact with bone reducing bone strength. Also, may stimulate apoptosis of osteoblasts leading to defective bone formation and so osteoporotic bone ${ }^{(6)}$.

Glycosuria in diabetic patients indirectly decreasing BMD through hypercalciuric effect and so decreased levels of serum calcium in the body thus hastening bone loss ${ }^{(7)}$. Some studies have shown low levels of vitamin D with altered vitamin D metabolism in patients with diabetic osteopenia ${ }^{(8)}$. Microvascular complications of diabetes lead to reduced blood flow to bone contributing to bone loss and fragility ${ }^{(9)}$.

However, obesity, widespread in type 2 diabetic patients, is associated with higher BMD, probably through mechanical loading effect and hormonal factors like insulin, estrogen, and leptin. Hyperinsulinemia may promote bone formation. However, with progression of the T2DM disease, low levels of insulin will be that may cause reduction of BMD $^{(10)}$.

\section{AIM OF THE WORK}

To measure and assess the bone mass density in type 2 diabetic patients either males or females. Also, studying other factors that may affect BMD like menopause and gender using DEXA scan densitometer.

\section{PATIENTS AND METHODS}


Signed written informed consent was taken from the patients to participate in the study.

\section{Ethcal approval:}

Approval for performing the study was obtained from Internal Medicine and Radiology Departments, Zagazig University Hospitals after taking Institutional Review Board (IRB) approval.

This case control study was implemented on ninety subjects including 60 diabetic patients and 30 nondiabetic subjects attending Internal Medicine Outpatients Clinics at Zagazig University Hospitals from June 2018 to December 2019. They were male and female aged 40 to 70 years.

It included a total number of 90 individual classified according to presence or absence of diabetes into:

Group 1: It included 30 healthy individual they were further subdivided according to sex into: Group 1 a: Male control group composed of ten (10) males with average age of $51.8 \pm 3.25$. Group $1 \mathbf{b}$ : Female control composed of twenty (20) diabetic patient further subdivided according to menstrual cycle into: (i) Ten premenopausal female control group with average age of $44.25 \pm 4.52$. (ii) Ten postmenopausal female control group with average age of $54.98 \pm 5.3$.

Group 2: It included 60 diabetic patient diagnosed according to ADA 2018 guidelines for diagnosis of diabetes ${ }^{(11)}$. They were further subdivided according to sex into: Group 2a: Male diabetic group composed of 20 males with average age of $56.4 \pm 6.25$. Group 2 b: Female diabetics composed of 40 diabetic patient further subdivided according to menstrual cycle into: (i) Twenty premenopausal female diabetic group with average age of $44.2 \pm 4.52 \mathrm{SD}$. (ii) Twenty postmenopausal female diabetic group with average age of $56.25 \pm 5.21 \mathrm{SD}$.

Exclusion criteria: Patients with chronic diseases affecting bone metabolism like liver cell failure, end stage renal diseases, malignancy, rheumatoid arthritis, systemic lupus erythematosus, parathyroid disease, Cushing disease, inflammatory bowel disease, malabsorption syndrome and those with abnormal level of serum calcium and phosphorus were excluded. Also, patients following medication which is known to affect calcium metabolism as long-term steroids, hormonal replacement therapy, phenytoin, eltroxin, heparin, thiazide diuretics, thiazolidinediones (TZDs) or those on calcium and Vit D supplementation in addition to patients with newly diagnosed diabetes less than 5 years were excluded.

All subjects (patients and controls) were underwent full history taking, clinical examination including BMI , necessary blood investigations including blood sugar parameters, renal chemistry, S. calcium and phosphorus, and DEXA scan examination.
Bone mineral density was the most important tool in the diagnosis of osteoporosis. We assessed BMD using DEXA scan densimeter (Ge WIPRO 2008 Lunar Model, Zagazig, Egypt) using X-ray equipment and a computer to measure bone density of RT neck femur and AP lumbar spine. The variables analyzed were age, time since menopause, gender, body mass index and duration of diabetes.

Assessment of anthropometric data: Anthropometric measurements including weight, height and waist measurements were obtained using standardized techniques. a) Height was measured with a tape to the nearest centimeter. b) Weight was measured with a traditional spring balance that was kept on a firm horizontal surface. c) Body mass index (BMI) was calculated by using the formula: weight $(\mathrm{Kg})$ / [height $\left(\mathrm{m}^{2}\right)$.

Assessment of blood glucose measurements (FBS, 2HPP or RBS): Are recorded on different -using pinprick check test- days before the study, using ADA 2018 normal reference ranges ${ }^{(\mathbf{1 1 1})}$ :

Normal $\quad$ FBS $<100 \quad$ RBS $<140 \quad 2$ HPP $<140$

Prediabetic FBS 100-125 RBS 140-199 2HPP 140-199

Diabetic FBS $>126$ RBS $>2002$ HPP $>200$.

Blood sample for lab study were obtained at the morning after 12 hours fasting for estimation of all parameters. Blood was aspirated into three plastic tubes; the first contained k-EDTA for HbAlc measurement. The second contained no additive for serum separation where serum creatinine, urea, albumin, calcium and phosphorus were estimated immediately and the third for $\mathrm{CBC}$.

Bone mineral density measurements: BMD was measured in the Rt proximal femur and AP lumbar spine and the data were analyzed on the basis of $\mathrm{T}$ score \& Z-score and areal BMD using the WHO criteria. $\mathrm{T}$ scores between -1 and -2.5 were considered to indicate osteopenia, and those equal or below -2.5 were considered to indicate osteoporosis.

\section{Data analysis}

BMD data of type 2 diabetic subjects were compared to those without diabetes matched for age using unpaired Student's t-test. Data were entered and analyzed using IBM SPSS (statistical package for the social sciences, Statistics software Inc., version 20.0, Armonk, NY: IBM Corp.). Descriptive statistics, Mean \pm SD and $t$ test $p<0.05$ was used as statistical test with 95\% confidence interval. Linear Correlation coefficient was used for detection of correlation between two quantitative variables in one group.

\section{RESULTS}


Table (1): Clinical characteristics and essential laboratory investigations of study population

\begin{tabular}{|c|c|c|c|c|c|}
\hline & \multirow{2}{*}{$\begin{array}{c}\begin{array}{c}\text { All Non-diabetic } \\
\text { Control group }\end{array} \\
\text { No. }=\mathbf{3 0} \\
\end{array}$} & \multirow{2}{*}{$\begin{array}{c}\begin{array}{c}\text { All Diabetic case } \\
\text { group }\end{array} \\
\text { No. }=60 \\
\end{array}$} & \multirow{2}{*}{$\begin{array}{l}\text { Test } \\
\text { of sig. }\end{array}$} & \multirow[t]{2}{*}{ P-value } \\
\hline & & & & & \\
\hline Age ( year ) & Mean \pm SD & $53.52 \pm 9.88$ & $55.28 \pm 10.25$ & 1.582 & NS \\
\hline Sex distribution & $\begin{array}{l}\text { Female } \\
\text { Male } \\
\end{array}$ & $\begin{array}{l}20(66.6 \%) \\
10(33.3 \%)\end{array}$ & $\begin{array}{l}40(66.6 \%) \\
20(33.3 \%) \\
\end{array}$ & 3.395 & NS \\
\hline BMI (KG/M2) & Mean \pm SD & $26.60 \pm 2.081$ & $27.92 \pm 3.378$ & 2.067 & $0.042 *$ \\
\hline RBS ( mg/dl) & Mean \pm SD & $118.26 \pm 3.84$ & $195.98 \pm 38.67$ & 10.948 & $<0.001$ \\
\hline $\begin{array}{l}\text { S. Creatinine } \\
(\mathrm{mg} / \mathrm{dl})\end{array}$ & Mean \pm SD & $1.04 \pm 0.12$ & $1.06 \pm 0.17$ & 0.512 & NS \\
\hline $\begin{array}{l}\text { S. Calcium } \\
\text { (mg/dl) }\end{array}$ & Mean \pm SD & $9.02 \pm 0.045$ & $8.62 \pm 0.91$ & 2.47 & $<0.05$ \\
\hline $\begin{array}{l}\text { S. Phosphorus } \\
(\mathrm{mg} / \mathrm{dl})\end{array}$ & Mean \pm SD & $3.56 \pm 0.48$ & $3.12 \pm 0.58$ & 3.569 & $<0.001$ \\
\hline
\end{tabular}

Clinical and laboratory Characteristics of the study populations with and without diabetes are given in Table (1).The mean age for diabetics was 53.3 years and nondiabetics was 55.2 years old. Both groups had a similar sex distribution with a female to male ratio $2: 1$. There was a statistically significant difference between the two groups regarding BMI. Serum creatinine values were higher among diabetic subjects but without any significant difference between both groups. Serum calcium and phosphorous levels were statistically significant lower among the diabetic group but they were still within the normal reference range among both groups.

Table (2): Distribution of bone mineral density among diabetics and nondiabetics

\begin{tabular}{|c|c|c|c|c|}
\hline \multirow[t]{2}{*}{ DEXA results } & $\begin{array}{l}\text { All Non-diabetic } \\
\text { control group }\end{array}$ & $\begin{array}{c}\text { All Diabetic case } \\
\text { group }\end{array}$ & \multirow{2}{*}{$\begin{array}{l}\text { Test of } \\
\text { sig. }\end{array}$} & \multirow[t]{2}{*}{ P-value } \\
\hline & No. $=30$ & No. $=60$ & & \\
\hline T score of $\mathrm{RT}$ proximal femur $(\mathrm{M} \pm \mathrm{SD})$ & $-0.827 \pm 0.282$ & $-1.376 \pm 0.428$ & 2.931 & $<0.03$ \\
\hline T score of Lumbar spine $(M \pm S D)$ & $-0.813 \pm 0.312$ & $-1.393 \pm 0.394$ & 2.563 & $<0.02$ \\
\hline $\begin{array}{l}\text { BMD G/cm2 of RT proximal femur (M } \\
\text { SD) }\end{array}$ & $0.924 \pm 0.28$ & $0.75 \pm 0.24$ & 4.87 & $<0.04$ \\
\hline BMD G/CM2 of lumbar spine $(\mathrm{M} \pm \mathrm{SD})$ & $0.853 \pm 0.35$ & $0.69 \pm 0.32$ & 4.98 & $<0.04$ \\
\hline Normal BMD & $25 / 30(83.3 \%)$ & $37 / 60(61.7 \%)$ & \multirow{3}{*}{5.11} & \multirow{3}{*}{ NS } \\
\hline Osteopenic & $4 / 30(13.3 \%)$ & $13 / 60(21.7 \%)$ & & \\
\hline Osteoporotic & $1 / 30(3.3 \%)$ & $10 / 60(16.6 \%)$ & & \\
\hline
\end{tabular}

Table (2) showed the BMD distribution among the study population. There was high statistically significant decrease of mean values of T score and Areal BMD G/CM2 among the diabetic group. And the majorty of abnormal BMD were among the diabetic group. Among the diabetic group, $61.7 \%$ of them had normal BMD and $38.3 \%$ had abnormal BMD. However among the non-diabetic group, $83.3 \%$ had normal BMD and only $16.6 \%$ had abnormal BMD with no significant difference was found in the groups regarding the BMD status distribution.

Table (3): Results of DEXA among non-diabetic males and diabetic males 


\begin{tabular}{|c|c|c|c|c|c|}
\hline \multirow{2}{*}{\multicolumn{2}{|c|}{ DEXA results }} & $\begin{array}{c}\text { Non-diabetic Males } \\
\text { control group }\end{array}$ & $\begin{array}{c}\text { Diabetic Males } \\
\text { Group }\end{array}$ & \multirow[b]{2}{*}{$\mathbf{X}^{2}$} & \multirow[b]{2}{*}{ Pvalue } \\
\hline & & No. $=10$ & No. $=20$ & & \\
\hline \multirow{2}{*}{ NORMAL } & NO & 10 & 17 & \multirow{6}{*}{1.66} & \multirow{6}{*}{ NS } \\
\hline & Percentage & $100 \%$ & $85 \%$ & & \\
\hline \multirow{2}{*}{ OSTEOPENIC } & NO & 0 & 3 & & \\
\hline & Percentage & $0 \%$ & $15 \%$ & & \\
\hline \multirow{2}{*}{ OSTEOPOROSIS } & NO & $\mathbf{0}$ & $\mathbf{0}$ & & \\
\hline & percentage & $0 \%$ & $0 \%$ & & \\
\hline
\end{tabular}

Table (3) showed the bone density status distribution among the studied groups. The control group which included 10 males individuals, all of them $(100 \%)$ were normal, with no one with osteopenia or osteoporosis. However the male diabetic group which included 20 patients, 17 patient $(85 \%)$ of them were normal, $3(25 \%)$ of them were osteopenic and no one with osteoporosis with no significant difference between the two studied groups ( $\mathrm{p}$ value 0.19 ).

Table (4): Results of DEXA among non-diabetic premenopausal and diabetic premenopausal females

\begin{tabular}{|c|c|c|c|c|c|}
\hline \multicolumn{2}{|c|}{ DEXA results } & \begin{tabular}{|c} 
Non-Diabetic \\
emenopausal females \\
group
\end{tabular} & $\begin{array}{c}\text { Diabetic Premenopausal } \\
\text { female group }\end{array}$ & $\mathbf{X}^{2}$ & \multirow[t]{2}{*}{ Pvalue } \\
\hline \multirow{3}{*}{ NORMAL } & & & & \multirow{7}{*}{1.71} & \\
\hline & NO & 8 & 13 & & \multirow{6}{*}{ NS } \\
\hline & Percentage & $80 \%$ & $65 \%$ & & \\
\hline \multirow{2}{*}{ OSTEOPENIC } & NO & 2 & 4 & & \\
\hline & Percentage & $20 \%$ & $20 \%$ & & \\
\hline \multirow{2}{*}{ OSTEOPOROSIS } & NO & $\mathbf{0}$ & 3 & & \\
\hline & Percentage & $0 \%$ & $15 \%$ & & \\
\hline
\end{tabular}

Table (4) showed the bone density status distribution among the studied groups. The control group which included 10 premenopausal female individual, 8 of them (80\%) were normal, $2(20 \%)$ were osteopenic and no one was osteoporotic. While the diabetic premenopausal female group which included 20 patients, 13 (65\%) of them were normal, $4(20 \%)$ were osteopenic and $3(15 \%)$ of them were osteoporotic. So, the percentage of abnormal bone density was relatively higher among the diabetic case group but didn't achieve statistically significant difference between the two groups.

Table (5): Bone density status according to DEXA results among non-diabetic postmenopausal females group and diabetic postmenopausal group

\begin{tabular}{|c|c|c|c|c|c|}
\hline \multicolumn{2}{|c|}{ DEXA results } & $\begin{array}{l}\text { Non-diabetic } \\
\text { Postmenopausal } \\
\text { females group }\end{array}$ & $\begin{array}{c}\text { Diabetic Postmenopausal } \\
\text { female group }\end{array}$ & $\mathbf{X}^{2}$ & P-value \\
\hline \multirow[b]{2}{*}{ NORMAL } & No & & & \multirow{6}{*}{3.5} & \multirow{6}{*}{ NS } \\
\hline & Percentage & $70 \%$ & $35 \%$ & & \\
\hline \multirow{2}{*}{ OSTEOPENIC } & NO & 2 & 6 & & \\
\hline & Percentage & $20 \%$ & $30 \%$ & & \\
\hline \multirow{2}{*}{ OSTEOPOROSIS } & NO & 1 & 7 & & \\
\hline & percentage & $10 \%$ & $35 \%$ & & \\
\hline
\end{tabular}

Table (5) showed the bone density status distribution among the studied groups. The postmenopausal control group which included 10 individual, 7 of them (70\%) were normal, two (20\%) were osteopenic and only one was osteoporotic. However the diabetic postmenopausal female group which included 20 patients, $13(65 \%)$ of them were normal, $6(35 \%)$ were osteopenic and $7(35 \%)$ were osteoporotic. This means that the percentage of abnormal bone mineral density was relatively higher among the diabetic cases than the controls but didn't achieve statistically significant difference between the two groups. 

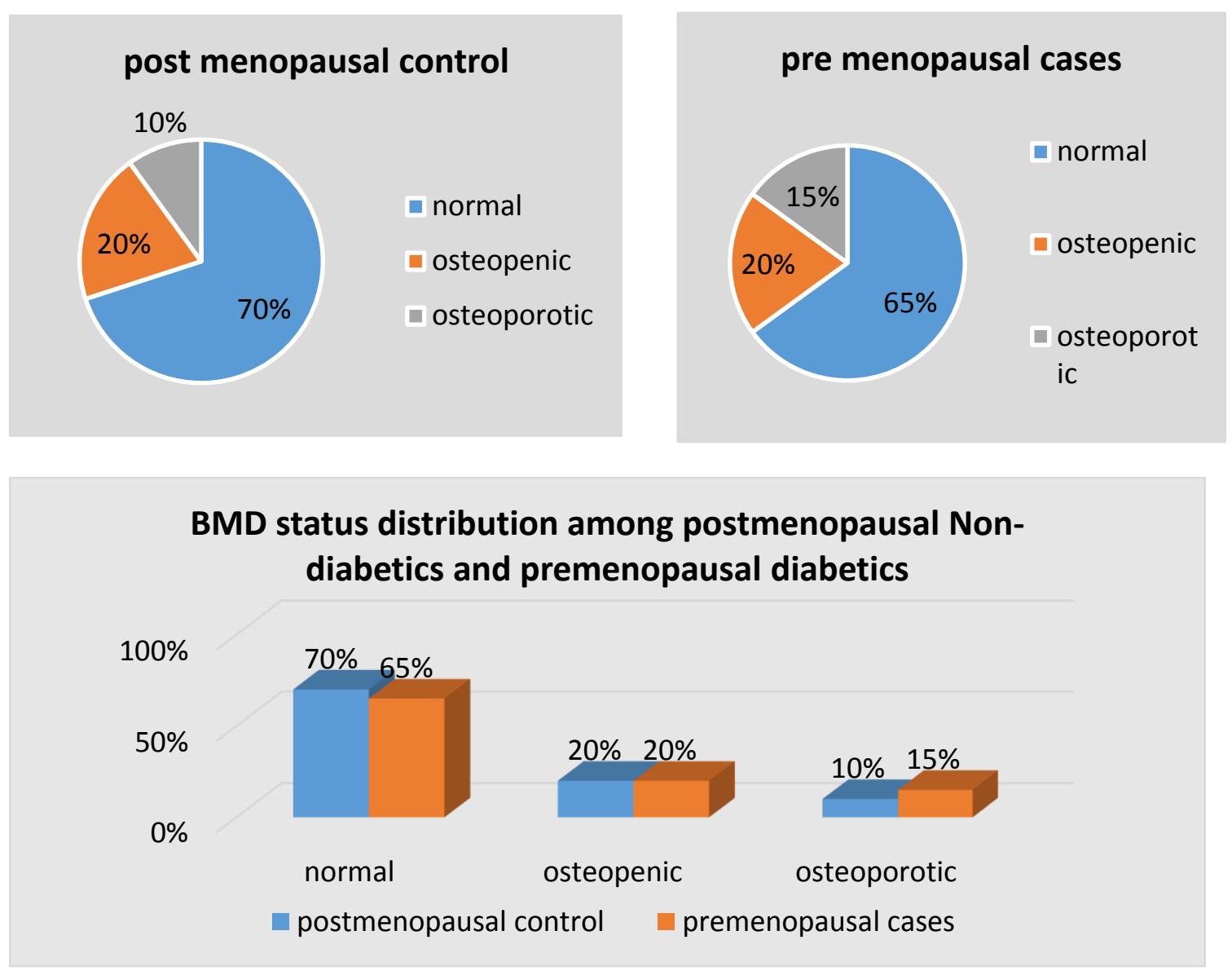

Figure (1): Illustrate bone status distribution among postmenopausal control and pre-menopausal diabetics Figure (1) showed that there was statistically significant difference in the mean value of serum phosphorus between the two groups with significant decrease among the premenopausal diabetic cases. There was statistically significant difference in the mean value of $\mathrm{T}$ score between the two groups with significant decrease among the premenopausal cases. There was no statistically significant difference in the mean value of areal BMD G/CM ${ }^{2}$ between the two groups, however it was obviously decreased among the premenopausal diabetic cases but didn't achieve significance. There was no significant difference in the bone density status distribution between the two groups with nearly equal percentages of bone status among them.

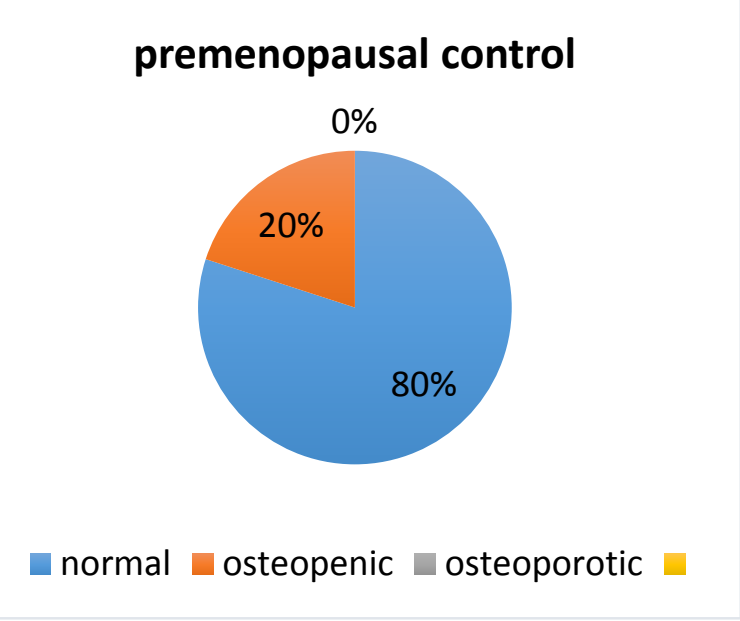

\section{postmenopausal cases}

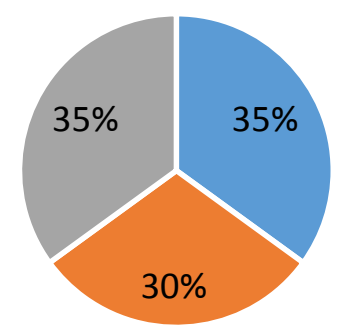

- normal - osteopenic - osteoporotic 


\section{Bone density status among premenopausal controls and postmenopausal diabetic cases}

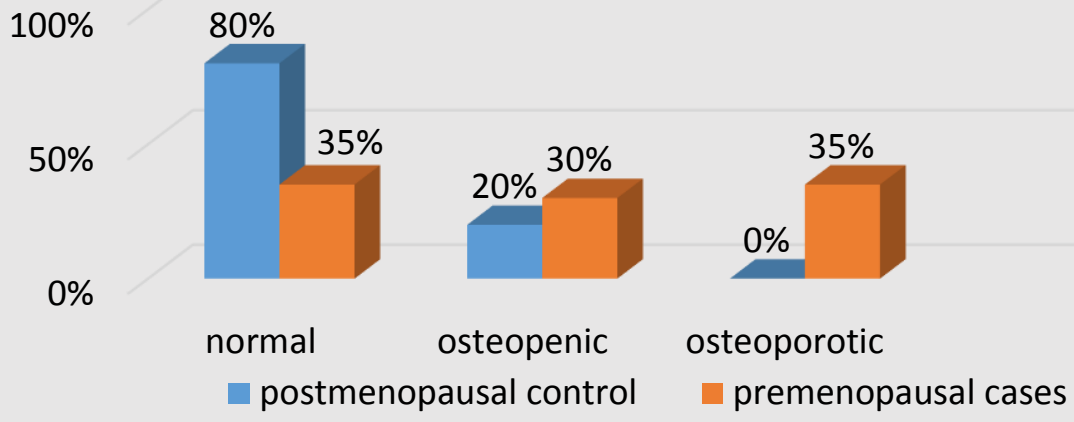

Figure (2): Illustrate bone density status among postmenopausal cases \&premenopausal controls. Figure (2) showed high statistically significant difference in the mean value of duration of DM (Y) between the two groups. Also, there was statistically significant difference in the mean values of serum phosphorus that was statistically significantly decreased among the cases. Moreover, there were statistically high significant difference in the mean values of BMD parameter between the two groups with significant decrease of both values among the postmenopausal cases. The percentage of abnormal BMD status was statistically significant higher among the postmenopausal diabetic cases $(65 \%)$ than of the premenopausal non-diabetic controls $(20 \%)$ with high significant difference.

Table (6): Comparison between all subgroups according to the T score and BMD G/CM ${ }^{2}$

\begin{tabular}{|c|c|c|c|c|c|c|c|c|}
\hline & $\begin{array}{l}\text { NON- } \\
\text { diabetic } \\
\text { Male } \\
\text { Control }\end{array}$ & $\begin{array}{l}\text { NON- } \\
\text { diabetic } \\
\text { Pre- } \\
\text { Ienopausal } \\
\text { Females }\end{array}$ & $\begin{array}{l}\text { NON- } \\
\text { diabetic } \\
\text { Post- } \\
\text { Ienopausal } \\
\text { Females }\end{array}$ & \begin{tabular}{|c} 
Diabetic \\
Male \\
cases
\end{tabular} & $\begin{array}{l}\text { Diabetic } \\
\text { Pre- } \\
\text { Menopausal } \\
\text { females }\end{array}$ & $\begin{array}{c}\text { Post- } \\
\text { nenopausal } \\
\text { Diabetic } \\
\text { females }\end{array}$ & $\begin{array}{l}\text { Test } \\
\text { f sign } \\
\text { (f) }\end{array}$ & Palue \\
\hline $\begin{array}{c}\text { T score of RT } \\
\text { proximal } \\
\text { femur }\end{array}$ & $\begin{array}{l}-0.728 \\
\pm 0.27 \\
\end{array}$ & $\begin{array}{l}-1.00 \\
\pm 0.638 \\
\end{array}$ & $\begin{array}{l}-0.812 \\
\pm 1.47 \\
\end{array}$ & $\begin{array}{c}-0.85 \\
\pm 0.273 \\
\end{array}$ & $\begin{array}{c}-1.32 \\
\pm 0.439 \\
\end{array}$ & $\begin{array}{l}-1.95 \\
\pm 1.09 \\
\end{array}$ & 9.85 & $<0.005$ \\
\hline $\begin{array}{c}\text { T score of } \\
\text { lumbar spine }\end{array}$ & $\begin{array}{l}-0.843 \\
\pm 0.41 \\
\end{array}$ & $\begin{array}{c}-0.933 \\
\pm 0.312 \\
\end{array}$ & $\begin{array}{r}-0.838 \\
\pm 1.39 \\
\end{array}$ & $\begin{array}{c}-0.93 \\
\pm 0.318\end{array}$ & $\begin{array}{l}-1.293 \\
\pm 0.394 \\
\end{array}$ & $\begin{array}{l}-2.10 \\
\pm 0.82 \\
\end{array}$ & 9.63 & k0.005 \\
\hline $\begin{array}{c}\text { BMD G/CM } \\
\text { of RT } \\
\text { proximal } \\
\text { femur }\end{array}$ & $\begin{array}{c}0.958 \\
\pm 0.241\end{array}$ & $\begin{array}{c}0.925 \\
\pm 0.305\end{array}$ & $\begin{array}{c}0.924 \\
\pm 0.255\end{array}$ & $\begin{array}{c}0.937 \\
\pm 0.225\end{array}$ & $\begin{array}{c}0.825 \\
\pm 0.211\end{array}$ & $\begin{array}{c}0.71 \\
\pm 0.236\end{array}$ & 8.25 & $k 0.005$ \\
\hline $\begin{array}{c}\text { BMD G/CM2 } \\
\text { of lumbar } \\
\text { spine }\end{array}$ & $\begin{array}{r}0.945 \\
\pm 0.35 \\
\end{array}$ & $\begin{array}{r}0.917 \\
\pm 0.35 \\
\end{array}$ & $\begin{array}{c}0.913 \\
\pm 0.241\end{array}$ & $\begin{array}{r}0.977 \\
\pm 0.32\end{array}$ & $\begin{array}{r}0.836 \\
\pm 0.32\end{array}$ & $\begin{array}{c}0.69 \\
\pm 0.216\end{array}$ & 8.73 & k0.005 \\
\hline
\end{tabular}

Table (6) showed that there was high statistically significant difference in the values of BMD parameters T-Score and Areal BMD among all the studied subgroups.

\section{DISCUSSION}

In our study, the mean duration of diabetes among the studied cases was 8 years that is in agreement with Athulya et al. ${ }^{(12)}$ study for Evaluation of bone mineral density among type 2 diabetes mellitus patients on 150 patients in South Karnataka in India and all patient cases were with type 2 DM.

In the present study, we compared the BMD parameters ( $\mathrm{T}$ score and Areal BMD G/CM ${ }^{2}$ values) of both right neck femur "HIP', and lumbar vertebral spine, between whole type 2 diabetic patients and whole non-diabetic control subject. There was a high statistical significant decrement of both values of BMD parameters of "neck femur and spine" among diabetic case group and non-statistically significant increase in the number of osteopenic and osteoporotic cases among them. Our results are in agreement with Yaturu (13) study that showed decrement of mean values of BMD 
parameters of hip in men with type $2 \mathrm{DM}$ and incidence of osteoporosis was significantly higher among diabetic subjects compared to age and body mass index matched non diabetic subjects. But in contrast to our study, the BMD of AP spine was significantly higher in diabetic subjects compared to non-diabetic mostly due to difference in the mean values of BMI as it showed similar density when subjects were matched for BMI. Wang et al. ${ }^{(14)}$ study is in agreement with our study where they sahowqed that correlation of BMD with disease duration and body mass index in elderly men with type 2 diabetes mellitus showed decrement of mean values of BMD parameters among type 2 diabetic patients. Also negative correlation of BMD parameters with "type 2 DM" disease duration. On the contrary to our results, Sumesh et al. ${ }^{(15)}$ study of association between BMD and T2DM showed a significantly higher increase in the BMD among diabetic patients than non-diabetics of both sex in different sites and showed a positive correlation of young age, male sex, higher body mass index and higher $\mathrm{HbA} 1 \mathrm{c}$ with higher BMD in diabetic patients.

Our study comparing its effect on male groups alone (control and diabetics) showed no significant difference in the BMD parameters either "T score or BMD G/CM ${ }^{2}$ " between the two groups. Also, there was no significant difference in the number of osteopenic or osteoporotic cases and this is in agreement with Thakur and Dash ${ }^{(16)}$ study that showed also no significant difference in bone mineral density among type 2 diabetes mellitus patients and controls in Western Odisha.

Type 2 DM effect among premenopausal female groups only whether control or cases showed no significant difference between controls and cases regarding the BMD parameters. Nevertheless there was non-significant increase in number of osteopenic and osteoporotic among diabetics.

Finally, its effect among postmenopausal females only either control or cases, there was statistically high significant decrease in the BMD parameters among the diabetic patients, and non-statistically significant increase in the number of osteopenic and osteoporotic cases among the diabetic patient. This is in agreement with Al-Matouq et al. ${ }^{(17)}$ study about prevalence of osteoporosis among postmenopausal females with type 2 diabetes mellitus in Saudi Arabia that showed decreased BMD among diabetics.

In contrast to our study, Hadzibegovic et al. ${ }^{(18)}$ and many studies on white women (19) showed that postmenopausal women with type $2 \mathrm{DM}$ had higher BMD among them. However, all of them (that shown increased BMD) were exposed to increased fracture risk and many of these study results were attributed to the increased BMI among diabetic patients ${ }^{\mathbf{2 0 , 2 1 )}}$.

We studied the effect of gender as a single factor on BMD by comparison between all males and all females either control or cases. Regarding controls the BMD parameters were decreased among females and the number of osteopenic and osteoporotic cases were also increased among them but didn't reach significance as Avdagić et al. (22) study showed.

Our study reported a high statistically significant decrease in the BMD parameters among the female cases and non-significant increase in the number of osteopenics and osteoporotics among them also. This is in agreement with Lei $\boldsymbol{e t}$ al. ${ }^{(23)}$ study about the effects of age, sex, weight, height, and BMI on BMD of elderly Chinese that showed significant lower BMD among females may be due to the faster rate of bone loss among females.

Other factors may be responsible for this discrepancy like limitations of areal BMD measurement and technical defect like noninvasive methods of bone measurement. The intrinsic limitation of measurement (e.g., areal BMD by DXA) is the two dimensional measurement of a three-dimensional structure which is liable to be confounded by bone size and body size- may be to have a role in both sex discrepancy (24).

Lastly we studied the effect of menopause on BMD through comparing of BMD between premenopausal control and postmenopausal control and also between premenopausal diabetics and postmenopausal diabetics. There was no significant difference between the two control groups pre or postmenopausal, however there was nearly significant difference between the two diabetic groups pre \& postmenopausal with nonstatistically significant increase in the number of osteopenics and osteoporotics case among the postmenopausal cases. The percentage of abnormal mineral density was $38.4 \%$ in diabetics while was 16.7 $\%$ in non-diabetics with the highest percentage were among the postmenopausal category of both groups $21.6 \%$ in the diabetic and $10 \%$ in the non-diabetics.

Our results are in agreement with Finkelstein et al. ${ }^{(25)}$, Riggs and Melton (26) study who stated that the most important risk factor for bone loss in midlife women is the menopause. It is also in agreement with "The Study of Women's Health across the Nation" (SWAN), which is a seven-center, longitudinal cohort study of the menopause transition in a communitybased sample of women from multiple ethnic groups. BMD of the lumbar spine and proximal femur has been measured annually in women at five SWAN sites and it showed that BMD changes were little during the pre- or early perimenopause but then began to decline substantially during the late perimenopause. BMD continues to decline rapidly during the early postmenopausal years. The annual rates of loss during these intervals were approximately $1.8-2.3 \%$ in the spine and $1.0-1.4 \%$ in the hip ${ }^{(27)}$. If bone loss was to continue at these rates for 5 years, the average woman's BMD would decline $7-10 \%$ in the spine and $5-7 \%$ in 
the hip, amounts that are associated with approximately 50-100\% higher fracture rates ${ }^{(28)}$.

In Our study, there was statistically significant difference observed in the BMI of the two main groups diabetics and non-diabetics, however there was no significant difference between subjects with normal and abnormal BMD either diabetics or control. And so did not signify any correlation between BMI and BMD. In diabetic subjects who had normal BMD their mean BMI was $27.6 \mathrm{~kg} / \mathrm{m}^{2}$ and in those with abnormal BMD mean their mean BMI was $28.4 \mathrm{~kg} / \mathrm{m}^{2}$. This was against a meta-analysis that had demonstrated BMI as an important predictor of BMD and that low BMI is associated with decreased BMD, increased risk of osteoporosis and increased risk of fracture ${ }^{(29)}$.

In our study, there was statistically high significant difference of mean values of serum calcium and phosphorus between the two main groups diabetics and non-diabetics. However, they still within the normal reference range- with significant decrease of both element among diabetic cases. This is in agreement with many studies which indicate that calcium metabolism plays a significant role in bone turnover, and that deficiency of calcium and vitamin D leads to diminished bone deposition. Moreover, the increased parathyroid hormone in response to low calcium levels increase bone resorption to safe guard enough calcium in blood. Calcitonin hormone produced by the parathyroid gland that increase bone deposition, is less effective as compared to PTH ${ }^{(30)}$.

There was a positive correlation between both serum calcium \& phosphorus and BMD. In our study a negative correlation was observed between the duration of diabetes and BMD. These results are consistent with the findings of Kao et al. ${ }^{(31)}$ and Wakasugi et al. ${ }^{(32)}$ studies who demonstrated that duration of diabetes is a risk factor for decreased BMD in T2DM subjects.

Our study also demonstrated a negative correlation between glycemic control and BMD. Those with abnormal BMD had a mean HbAIc of $8.1 \%$ and those with normal BMD had a mean HbAIc of $6.8 \%$, which showed statistically significant difference. The mean fasting blood sugar among diabetics with normal BMD was $122 \mathrm{mg} / \mathrm{dl}$ and those with abnormal BMD was 174 $\mathrm{mg} / \mathrm{dl}$ and the differences were statistically significant. These findings are in agreement with Okazaki et al. ${ }^{(33)}$ study who found that metabolic improvements in poorly controlled T2DM decreased bone loss within a short period.

\section{CONCLUSION}

T2DM negatively affect the bone strength through affection of BMD. Many factors play a pivotal role with diabetes for affection of BMD including gender, age, duration of diabetes and menopause. Level of serum calcium and phosphorus in T2DM may be a marker for BMD status.

All T2DM should be evaluated for the risk of osteoporosis by BMD assessment and should be offered appropriate preventive measures.

\section{REFERENCE}

1. Strotmeyer ES, Cauley JA, Orchard TJ et al. (2006): Middle-aged premenopausal women with type 1 diabetes have lower bone mineral density and calcaneal quantitative ultrasound than nondiabetic women. Diabetes Care, 29: 306-311.

2. Barrett-Connor E, Holbrook TL (1992): Sex differences in osteoporosis in older adults with noninsulin-dependent diabetes mellitus. JAMA., 268: 33337.

3. Wakasugi M, Wakao R, Tawata M et al. (1993): Bone mineral density measured by dual energy $x$-ray absorptiometry in patients with non-insulin-dependent diabetes mellitus. Bone, 14: 29-33.

4. Reid IR, Evans MC, Cooper GJ et al. (1993): Circulating insulin levels are related to bone density in normal postmenopausal women. Am J Physiol., 265 (4 Pt 1): 655-659.

5. Paul RG, Bailey AJ (1996): Glycation of collagen: The basis of its central role in the late complications of ageing and diabetes. Int J Biochem Cell Biol., 28: 1297-310.

6. Alikhani M, Alikhani Z, Boyd C et al. (2007): Advanced glycation end products stimulate osteoblast apoptosis via the MAP kinase and cytosolic apoptotic pathways. Bone, 40: 345-53.

7. Pittas AG, Lau J, Hu FB et al. (2007): The role of Vitamin D and calcium in type 2 diabetes. A systematic review and meta-analysis. J Clin Endocrinol Metab., 92: 2017-29.

8. Kao WH, Kammerer CM, Schneider JL et al. (2003): Type 2 diabetes is associated with increased bone mineral density in Mexican-American women. Arch Med Res., 34: 399-406.

9. Bonjour JP, Chevalley T, Rizzoli R et al. (2007): Geneenvironment interactions in the skeletal response to nutrition and exercise during growth. Med Sport Sci., 51: 64-80.

10. Bacchetta J, Boutroy S, Juillard L et al. (2009): Bone imaging and chronic kidney disease: Will high-resolution peripheral tomography improve bone evaluation and therapeutic management? J Ren Nutr., 19: 44-9.

11. American Diabetes Association (ADA) (2018): Standards of Medical Care in Diabetes. https://diabetesed.net/wp-content/uploads/2017/12/ 2018-ADA-Standards-of-Care.pdf

12. Athulya GA, Jaganathan J, Philip R et al. (2017): Evaluation of bone mineral density among type 2 diabetes mellitus patients in South KarnatakaJ Nat Sci Biol Med., 8 (1): 94-98.

13. Yaturu S (2009): Diabetes and skeletal health. Journal of Diabetes, 1: 246-254.

14. Wang XR, Pei Y (2008): Correlation of bone mineral density with disease duration and body mass in elderly men with type 2 diabetes mellitus. J Clin Rehab Tissue Eng Res., 15: 2891-2894. 
15.Sumesh R, Baiju SJ, Rajesh V et al. (2014): Association between Bone Mineral Density and Type 2 Diabetes Mellitus- An Original Article. British Journal of Research, 2: 063-067.

16. Thakur AK, Dash S (2018): International Journal of Research in Medical Sciences Thakur AK. Int J Res Med Sci., 6 (2): 459-464.

17.Al-Matouq MA, El-Desouki MI, Othman SA et al. (2004): Prevalence of ostteoporosis among postmenopausal females with diabetes mellitus. Saudi Med J., 25: 1423-7.

18. Hadzibegovic I, Miski B, Cosic V et al. (2008): Increased bone mineral density in postmenopausal women with type 2 diabetes mellitus. Ann Saudi Med., 28 (2): 102-104.

19. Akin O, Gol K, Akturk M et al. (2003): Evaluation of bone turnover in postmenopausal patients with type 2 diabetes mellitus using biochemical markers and bone mineral density measurements. Gynecol Endocrinol., 17(1):19-29.

20. Vestergaard $P$ (2007): Discrepancies in bone mineral density and fracture risk in patients with type 1 and type 2 diabetes: A meta-analysis. Osteoporos Int., 18: 427-44.

21. De Luis Roman DA, Aller R, Perez-Castrillon JL et al. (2004): Effects of dietary intake and life style in patients with diabetes mellitus type 2. Ann Nutr Metab., 48: 1415.

22. Avdagić SC, Barić IC, Keser I et al. (2009): Differences in peak bone density between male and female students. Arh Hig Rada Toksikol., 60 (1): 79-86.

23. Lei SF, Deng FY, Li MX et al. (2004): Bone mineral density in elderly Chinese: effects of age, sex, weight, height, and body mass index. Hong-Wen Deng J Bone Miner Metab., 22: 71-78.
24.Seeman E (1997): From density to structure: growing up and growing old on the surfaces of bone. J Bone Miner Res., 12: 509-521.

25. Finkelstein JS (2004): Osteoporosis. In: Goldman L, Ausiello D, eds. Cecil textbook of medicine. $22^{\text {nd }}$ ed. Philadelphia, Saunders, Pp: 1547-1555.

26. Riggs BL, Melton III LJ (1992): The prevention and treatment of osteoporosis. Engl J Med., 327: 620-627.

27. Finkelstein JS, Brockwell SE, Mehta V et al. (2008): Bone mineral density changes during the menopause transition in a multiethnic cohort of women. J Clin Endocrinol Metab., 93 (3): 861-868.

28. Marshall D, Johnell O, Wedel H (1996): Meta-analysis of how well measures of bone mineral density predict occurrence of osteoporotic fractures. BMJ., 312: 12541259.

29. Vestergaard P, Rejnmark L, Mosekilde L (2005): Relative fracture risk in patients with diabetes mellittus, and the impact of insulin and oral antidiabetic medication on relative fracture risk. Diabetologia, 48: 1292-1299.

30.Jacqueline G (2015): Parathyroid hormone, calcitonin and vitamin $\mathrm{D}$ testing in calcium and bone metabolic disorders. Medlab Magazine, 26: 28-32.

31. Kao WH, Kammerer CM, Schneider JL et al. (2003): Type 2 diabetes is associated with increased bone mineral density in Mexican-American women. Arch Med Res., 34: 399-406.

32. Wakasugi M, Wakao R, Tawata M et al. (1993): Bone mineral density measured by dual energy $\mathrm{x}$-ray absorptiometry in patients with non-insulin-dependent diabetes mellitus. Bone, 14: 29-33.

33. Okazaki R, Totsuka Y, Hamano K et al. (1997): Metabolic improvement of poorly controlled noninsulin dependent diabetes mellitus decreases bone turnover. J Clin Endocrinol Metab., 82: 2915-2920. 